\section{Erectile dysfunction and smoking: subverting tobacco industry images of masculine potency}

\section{S Chapman}

\section{Rather than enhance masculinity, smoking has the exact opposite effect}

5 a or all the transitory fashions in approaches about how best to motivate smokers to quit, studies of exsmokers and attempting quitters repeatedly affirm that the primary motivation for stopping smoking remains concern about health consequences-both in the future and those already being experienced. ${ }^{1}$ Despite folklore about youth being indifferent about their future health, there is evidence that health concerns motivate cessation among young smokers $^{23}$ as well as in older smokers closer to slipping off life's mortal coil. ${ }^{4}$ There is typically daylight between smokers' nomination of health concerns and all other motivations like cost, social unacceptability and concerns about being smelly. This understanding and the mounting evidence that scare campaigns cause quitline meltdown and precipitate cessation ${ }^{6}$ has seen a global renaissance in efforts to worry smokers about the consequences of basting one's lungs with tobacco smoke-some 87000 times a year if you are a 20 a day, 12 puff per cigarette smoker.

\section{GRIM WARNINGS}

Barely an organ or function of the body escapes the cornucopia of horrors that smoking causes. Grim prime-time TV ads and graphic pack warnings have shown smokers what gangrene from peripheral vascular disease looks like (although scratch and sniff "educational" cards impregnated with the unforgettable odours of putrescene or cadaverine have yet to surface). Tobacco industry advertising positioning smoking as being about discernment, judgement and elegance has had to compete with pictures from autopsy showing what a brain haemorrhage during a stroke looks like. ${ }^{8}$ A surgical gloved hand squeezing gelatinous atheroma from a smoker's aorta ${ }^{8}$ has disturbed the complacent ambiance of countless smokers' living rooms in the over 30 countries now using the Australian
"Every cigarette is doing you damage" campaign.

Clinical reports of associations between smoking and erectile dysfunction have been around now for some years. In 2000, these reports were given strong support by a cohort study showing a near doubling in the incidence of impotence in smokers. ' Impotency warnings are appearing on some nations' graphic pack warnings. My favourite is the disconsolate Brazilian couple contemplating a long night after the debonair male's wedding tackle failed to fire (fig 1).

In this issue, a large cross sectional study from Australia ${ }^{10}$ shows that the adjusted odds ratio of a 40-49 year old smoker having prolonged erectile problems compared to a non-smoker is 3.50, rising to 5.96 for smokers aged 50-59 years. With one in 10 of all men in the study reporting prolonged erectile impotency treatments cashing in on the anxiety this causes, sexual impotency plainly has enormous potential to bring a new saliency to the health and personal consequences of smoking.

\section{IMPOTENCE MESSAGE}

However, some within the tobacco control fraternity are circumspect about the enthusiasm for impotence warning messages. Their argument runs that because impotence is uncommon in younger men, and that widespread advertising for campaigns for impotency therapies construct impotence as a fate awaiting middle and older aged men, that young smokers will greet such messages with incredulity and discount any concern because of its distant threat. This scepticism may even spill over to other warnings. They see the impotence message as alas lending titillating, prurient and possibly a trivialising edge to what they believe ought to be a more "deadly" message. Focus group testing of candidate messages for the recent introduction of graphic pack warnings in Australia saw an impotency warning problems and the manufacturers of discarded after those interviewed suggested the warning was unbelievable and "easily laughed off". ${ }^{11}$ However, such a reaction may well have reflected a group dynamics issue in the context of the research setting, with men being ill at ease in admitting concern about erectile problems in front of other men. So is this pessimism reasonable?

Such criticisms can of course also be levelled at all health focused messages because age is the single biggest predictor of the onset of disease and far fewer young compared to older smokers have had personal experience of such outcomes. Like all chronic disease caused and aggravated by smoking, erectile dysfunction is not an acute effect of smoking, but a consequence that develops from years of vascular assault.

Importantly, Doll et al's 50 year follow up of their British male doctor cohort reminds us that "those who stopped before middle age [age 40]... had a pattern of survival similar to that of men who had never smoked". ${ }^{12}$ Cardiovascular damage from smoking can reverse with smoking cessation and early signs of impotency, generating the distress it can, may act as a powerful motivator for life saving cessation in middle aged men.

Even the most corpulent tobacco control campaign budgets pale into insignificance alongside those for mainstream consumer goods. Experienced tobacco control campaigners understand well that controversial, conversation-generating health advertising can

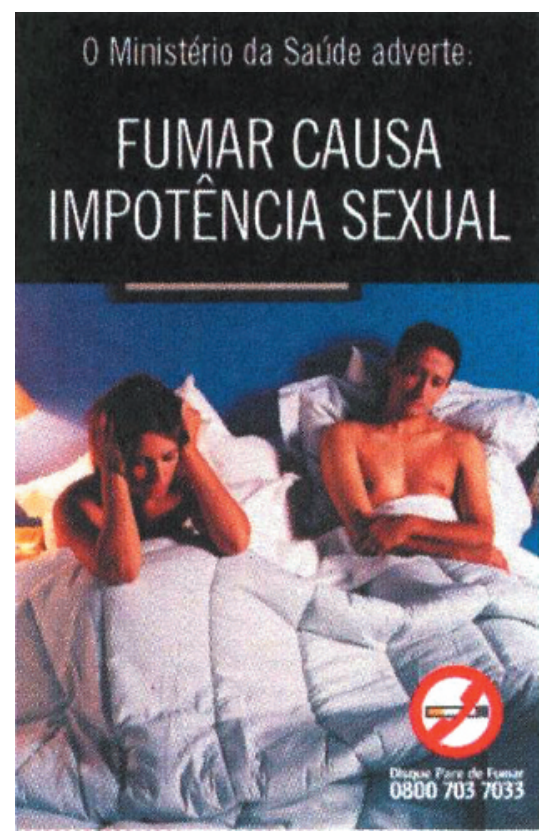

Figure 1 Brazilian health warning: "Smoking causes sexual impotence" 
often generate far greater exposure via associated news coverage and media debate than the ads themselves. ${ }^{13} 14$

The impotency issue also holds potential to subvert decades of tobacco industry cultivation of smoking as a symbol of male potency. If widespread publicity came to forge a natural apposition between the cigarette and a vision of a flaccid dejected penis, the semiotics of smoking may change radically.

Tobacco Control 2006;15:73-74.

doi: $10.1136 /$ tc. 2006.016063

Correspondence to: Professor Simon Chapman, School of Public Health, University of Sydney, Building A 27, Sydney, NSW 2006, Australia; simonchapman@health.usyd.edu.au

\section{REFERENCES}

1 Hyland A, Li Q, Bauer JE, et al. Predictors of cessation in a cohort of current and former smokers followed over 13 years. Nicotine Tob Res 2004;6(suppl 3):S363-9.

2 Riedel BW, Robinson LA, Klesges RC, et al. What motivates adolescent smokers to make a quit attempt? Drug Alcohol Depend 2002;68:167-74

3 Aung AT, Hickman NJ, Moolchan ET. Health and performance related reasons for wanting to quit: gender differences among teen smokers. Subst Use Misuse 2003;38:1095-107.

4 Yong HH, Borland R, Siahpush M. Quittingrelated beliefs, intentions, and motivations of older smokers in four countries: findings from the International Tobacco Control Policy Evaluation Survey. Addict Behav 2005;30:777-88.

5 Carroll T, Rock B. Generating Quitline calls during Australia's National Tobacco Campaign: effects of television advertisement execution and programme placement. Tob Control 2003;12(suppl II):ii40-4.

6 White V, Hill D, Siahpush M, et al. How has the prevalence of cigarette smoking changed among Australian adults? Trends in smoking prevalence between 1980 and 2001. Tob Control 2003;12(suppl II):ii67-74.

7 Hill D, Chapman S, Donovan R. The return of scare tactics. Tob Control 1998;7:5-8.

8 Anon. http://tobacco.health.usyd.edu.au/tds/ details.jsp?document_id = TVC20000000.
9 Felman H, Johannes C, Derby C, et al. Erectile dysfunction and coronary risk factors: prospective results from the Massachusetts male aging study. Prev Med 2000;30:328-38.

10 Millett C, Wen LM, Rissel C, et al. Smoking and erectile dysfunction: findings from a representative sample of Australian men. Tob Control 2006;15:136-9.

11 Shanahan P. Evaluation of the health warnings and explanatory health messages on tobacco products. Prepared for Tobacco and Alcohol Strategies Section, Department of Health and Aged Care, Australian Government. November 2000. http://www.health.gov.au/internet/ wcms/Publishing.nsf/Content/health-pubhlth strateg-drugs-tobacco-warnings.htm/\$FILE/ warnings.pdf.

12 Doll R, Peto R, Boreham J, et al. Mortality in relation to smoking: 50 years' observations on male British doctors. BMJ 2004;328:1519.

13 Durrant R, Wakefield M, McLeod K, et al. Tobacco in the news: an analysis of newspaper coverage of tobacco issues in Australia, 2001 Tob Control 2003;12(suppl II):ii75-81.

14 Smith KC, Terry-McElrath Y, Wakefield $M$, et al. Media advocacy and newspaper coverage of tobacco issues: a comparative analysis of 1 year's print news in the United States and Australia. Nicotine Tob Res 2005;7:289-99.

\section{$\mathrm{ECHO}$}

Investigating the relation between placement of Quit antismoking advertisements
and number of telephone calls to Quitline: a semiparametric modelling approach

Bircan Erbas, Quang Bui, Richard Huggins, Todd Harper, Victoria White

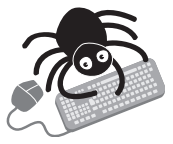

Please visit the Tobacco

Control website [www.

tobaccocontrol. com] for a link to the full text of this article.
Study objectives: Quitline-an antismoking advertising and a telephone helpline service-is an effective public health intervention strategy for tobacco control. The objective of this short report is to model the relation between placement of antismoking advertisements and calls to Quitline on a given day.

Methods/design: Data on daily Quitline antismoking advertisements, television target audience rating points (TARPS), and calls to Quitline Victoria were studied for the period 1 August 2000 and 31 July 2001. The outcome-calls to Quitline-is a count and thus assumed to follow a Poisson distribution. Generalised partial linear models were used to model the logarithm of mean daily calls as a non-parametric function of time and a linear parametric function of the day of week, number of advertisements, and TARPS.

Main results: Peak calls to Quitline Victoria occurred during Monday to Wednesday with around three times as many calls compared with Sunday. Both placement of Quitline advertisements $(\mathrm{p}<0.001)$ and an increase in TARPS $(\mathrm{p}<0.001)$ on a given day significantly increased the number of calls made to Quitline Victoria. The model adequately captured fluctuations in call volume and diagnostics showed no model inadequacy.

Conclusions: In this short report the emphasis is on modelling the parametric components-day of week, placement of advertisements, and TARPS on call volume. The dynamics of the underlying time trend in call volume is captured in a non-parametric component. Future analysis of hourly data would provide additional information to assess different media buying strategies that might increase call volume.

A Journal of Epidemiology and Community Health 2006;60:180-182. 